University of Wollongong

Research Online

Faculty of Business - Papers (Archive)

Faculty of Business and Law

$1-1-2019$

Parent and child perceptions of gambling promotions in Australian sport

Jennifer David

jd741@uowmail.edu.au

Samantha L. Thomas

slthomas@uow.edu.au

Melanie J. Randle

University of Wollongong, mrandle@uow.edu.au

Hannah Pitt

hlp674@uowmail.edu.au

Mike Daube

m.daube@curtin.edu.au

Follow this and additional works at: https://ro.uow.edu.au/buspapers

Part of the Business Commons

Research Online is the open access institutional repository for the University of Wollongong. For further information contact the UOW Library: research-pubs@uow.edu.au 


\title{
Parent and child perceptions of gambling promotions in Australian sport
}

\begin{abstract}
Gambling is recognized as a significant public health problem. However, there is little research exploring community attitudes towards gambling and the development of advocacy initiatives. Engaging adults and young people in advocacy efforts is recognized as being beneficial to the successful implementation of harm prevention and reduction strategies. This study explored the attitudes of young people and their parents towards the alignment of gambling with sport, and the strategies they perceive could be used to prevent and reduce gambling related harm. Using a Constructivist Grounded Theory approach, 30 family groups from Melbourne, Australia participated in semi-structured interviews. Parents and young people were asked about gambling and its promotion, alignment with sporting codes, the potential impact on young people and strategies that may prevent or reduce gambling harm. Thematic analysis was undertaken to interpret the data. The sample comprised 29 parents, one grandparent and 48 young people. Themes emerging from the data related to the use of imagery and appeal strategies in advertisements, the normalization of betting in advertisements and the alignment of betting with sport. Parents and young people also identified a number of potential gambling harm prevention and reduction initiatives. Parents and young people were able to describe a range of strategies used by gambling companies to promote their products, understand the potential impact of these strategies, and recommend strategies to reduce harm. Given this level of understanding there is clearly an opportunity to engage young people and stakeholders in advocacy initiatives aimed at reducing and preventing gambling harm.
\end{abstract}

Disciplines

Business

Publication Details

David, J. L., Thomas, S. L., Randle, M., Pitt, H. \& Daube, M. (2019). Parent and child perceptions of gambling promotions in Australian sport. Health Promotion International, Online First 1-11. 
1 Parent and child perceptions of gambling promotions in Australian sport

2 Jennifer L. David. Deakin University, Geelong Australia. Centre for Population Health

3 Research, Faculty of Health. jdavid@deakin.edu.au

Samantha L. Thomas. Deakin University, Geelong Australia. Centre for Population Health Research, Faculty of Health. samantha.thomas@deakin.edu.au

Melanie Randle. University of Wollongong, Wollongong Australia. Faculty of Business, School of Management, Operations and Marketing.mrandle@uow.edu.au

Hannah Pitt. Deakin University, Geelong Australia. Centre for Population Health Research, Faculty of Health. hannah.pitt@deakin.edu.au

Mike Daube. Curtin University, Perth Australia. Faculty of Health Sciences. M.Daube@curtin.edu.au

Corresponding Author: Jennifer L. David, Deakin University, Geelong Australia. Centre for Population Health Research, School of Health and Social Development, Faculty of Health. e. jdavid@deakin.edu.au

\section{Competing interests}

JD has no competing interests to declare. ST receives funding from the Australian Research Council and the Victorian Responsible Gambling Foundation for gambling research. The Victorian Responsible Gambling Foundation is funded via hypothecated taxes from gambling. In the last three years she has received consultancy funding for elite athlete gambling harm education from the AFL Players Association and AFL Sportsready, and conference travel funding from the Living Room, Cardiff and the European Union. MR receives funding from the Victorian Responsible Gambling Foundation for gambling research. MD and HP receive funding from the Australian Research Council and the Victorian Responsible Gambling Foundation for gambling research.

\section{Funding}

JD is the recipient of an Australian Government Research Training Program Scholarship. This research was funded by an Australian Research Council Discovery Grant [DP140102210].

\section{Ethical approval}

Ethical approval was obtained from Deakin University Human Research Ethics Committee (HEG_2016-064). Participants provided written and verbal consent to participate.

\section{Authors' contributions}

JD: Contributed to the development of the analytical framework. Collected and analysed data, prepared the first draft of the manuscript and critically revised paper. ST: Study Chief Investigator. Contributed to the development of the analytical framework. Analysed data, drafted paper and critically revised paper. MR: Contributed to the development of the analytical framework. Analysed data, drafted paper and critically revised paper. 
51 HP: Contributed to the development of the analytical framework, data collection, data 52 interpretation, and the critical revision of the paper.

53 MD: Study Chief Investigator. Contributed to data interpretation, and the critical 54 revision of the paper.

55 Word Count: 7,231 including abstract (original article) 


\begin{abstract}
(250 words)
Gambling is recognised as a significant public health problem. However there is little research exploring community attitudes towards gambling and the development of advocacy initiatives. Engaging adults and young people in advocacy efforts is recognised as being beneficial to the successful implementation of harm prevention and reduction strategies. This study explored the attitudes of young people and their parents toward the alignment of gambling with sport, and the strategies they perceive could be used to prevent and reduce gambling related harm. Using a Constructivist Grounded Theory approach, 30 family groups from Melbourne, Australia participated in semi-structured interviews. Parents and young people were asked about gambling and its promotion, alignment with sporting codes, the potential impact on young people and strategies that may prevent or reduce gambling harm. Thematic analysis was undertaken to interpret the data. The sample comprised 29 parents, one grandparent and 48 young people. Themes emerging from the data related to the use of imagery and appeal strategies in advertisements, the normalisation of betting in advertisements, and the alignment of betting with sport. Parents and young people also identified a number of potential gambling harm prevention and reduction initiatives. Parents and young people were able to describe a range of strategies used by gambling companies to promote their products, understand the potential impact of these strategies, and recommend strategies to reduce harm. Given this level of understanding there is clearly an opportunity to engage young people and stakeholders in advocacy initiatives aimed at reducing and preventing gambling harm.
\end{abstract}

Keywords: parents, young people, gambling, public health, advocacy 


\section{Background (5,826 words)}

84

Overview: Engaging communities in public health advocacy and policy

86

87 Researchers have identified that the overall aim of health advocacy is to improve the wellbeing of communities by advocating for healthy public policy and supportive environments, mediating between different groups in society to improve health, and enabling communities to achieve optimal outcomes (Kickbusch, 1995, Carlisle, 2000). Along with the capacity building function of advocacy (Carlisle, 2000) which is

92 fundamental in the promotion of health equity (Potvin et al., 2003), the important role of public participation and engagement in health advocacy movements is well documented in the literature (Montini et al., 2010). Those working in public health and health promotion recognise the need to engage with individuals (and groups) in the context of their communities, with evidence suggesting that by incorporating the views of target populations, preventive public health and health promotion initiatives are more likely to succeed (Hesketh et al., 2005).

99

Although some literature argues that community support and participation are not necessarily a prerequisite for successful policy implementation, the value of community engagement in policy implementation is acknowledged (Rosenberg et al., 2012). The literature also notes the benefits of community engagement in prevention and promotion strategies (World Health Organization, 1986). Further, research has found that public opinion and public policy support are often inter-related, with researchers stating that public opinion may influence public policy decisions and vice

107 versa (Tobin et al., 2011). 
109 Researchers have highlighted the importance of engaging with young people when

110 developing campaigns and policies that focus on issues that have an impact on their

111 health and wellbeing (Odukoya et al., 2015). Youth-focused advocacy efforts in

112 public health and health promotion have been important in highlighting the need for

113 greater awareness among this group as to the harms associated with unhealthy

114 commodity products and initiatives aimed at reducing these harms (Conlisk et al.,

115 2006). For example, young people have identified the promotion of unhealthy

116 products such as junk food in sport as being contradictory to the purpose of

117 engaging in physical activity and playing sport and are supportive of measures to

118 address these types of relationships (Smith et al., 2017). Young people have also

119 demonstrated a clear capacity to engage in discussions about policy issues that

120 impact upon them. For example, in a study exploring young people's perceptions of

121 current and future policies to reduce and prevent harm associated with alcohol and

122 other drug use, researchers found that young people had a clear understanding of

123 issues pertinent to them, could recommend various prevention strategies, and

124 wished to engage in policy deliberation (Lancaster et al., 2014). Young people's

125 engagement in public health and health promotion strategies has also been

126 important in understanding which strategies they perceive would be less effective in

127 improving their health and wellbeing. For example, a study exploring young people's

128 attitudes towards tobacco control policies demonstrated that although young people

129 perceived some public health interventions to be effective on a broader population

130 level, the same strategies were perceived as less effective in changing the behaviour

131 of young people (Crawford et al., 2002). 
135 Gambling is recognised as a significant public health issue in many countries, with

136 recent commentary focusing on the alignment of gambling promotions with sport,

137 and in particular the impact of these promotions on young people (Pitt et al., 2016a,

138 Bestman et al., 2015, Thomas et al., 2016a). In the last five years there has been

139 growing community concern in countries such as Australia and the United Kingdom

140 about the impact of sports betting marketing in normalising gambling for young

141 people and the potential consequences of this on future attitudes and behaviours of

142 young people (Pitt et al., 2017a, Pitt et al., 2017b, Lopez-Gonzalez et al., 2017).

143 Research has found that young people have significant brand recall and awareness

144 of gambling companies. This includes: 1) being able to identify multiple sports betting

145 brands (Thomas et al., 2016a); 2) identifying specific sports betting promotions and

146 sponsorship relationships with sporting teams and codes (Thomas et al., 2016a) and

147 3) perceiving that gambling is a common part of sport (Pitt et al., 2016a, Pitt et al.,

148 2017b). Further research has found that sports betting marketing has the potential to

149 positively influence young people's future gambling intentions and that some young

150 people perceive the saturation of sports betting advertisements as being

151 representative of the product's popularity (Pitt et al., 2017a). Young people and their

152 parents also perceive that sports betting advertising depicts wagering as being highly

153 accessible and an easy way to make money (Pitt et al., 2016b). Research in

154 Australia exploring community attitudes toward gambling suggests that the

155 community is supportive of various gambling harm reduction strategies (Thomas et

156 al., 2017, McAllister, 2014, FARE Australia, 2017), particularly those that aim to ban

157 or reduce gambling advertisements during televised sport, gambling advertisements 
158 at gambling venues, and gambling sponsorship of sport (Thomas et al., 2017).

159 Further Australian research has found that young people believe that sporting codes

160 need to do more to protect them from exposure to sports betting advertisements,

161 particularly through the implementation of advertising restrictions and bans (Thomas

162 et al., 2018).

163

164 Research that seeks to explore young people's (and their parents') understanding of gambling industry strategies and their views on public health strategies to prevent and reduce harm may be particularly powerful in helping public health and health

167 promotion practitioners advocate for regulatory and policy change. The aim of this research was to explore the attitudes of young people and their parents about the alignment of gambling with sport and the strategies they perceived could assist in the prevention and reduction of gambling related harm. The data presented in this paper explores four research questions:

1. What do parents and young people perceive are the promotional strategies used by the gambling industry in the context of sports?

2. What impact do parents and young people perceive that these promotional strategies may have on the attitudes and future behaviours of young people?

3. What strategies do parents and young people perceive could be used to prevent and reduce gambling related harm?

4. What strategies could be used to more effectively build community based capacity when advocating for gambling reform?

\section{Methods}


Approach and study design

186 The data presented in this paper was part of a broader qualitative study with parents

187 and young people, which aimed to explore attitudes towards the relationship

188 between gambling and sport. A Constructivist Grounded Theory (CGT) approach was used to guide the development of the research questions and the collection and analysis of the data in this study (Charmaz, 2006). In this approach a partnership is created between the researcher and the participants thus acknowledging the role of experiences and bias in research development and analysis (Charmaz, 2006). The use of a CGT approach was considered most appropriate for this study as it recognises the subjective nature of data collection and analysis due to this engagement (Charmaz, 2006).

\section{Participant recruitment}

199 Family groups consisting of one parent or caregiver and at least one child living in metropolitan Melbourne, Australia, were initially approached using convenience sampling techniques (Ritchie et al., 2014). Information about the study was

202 distributed to the researchers' social networks as well as local community and

203 sporting clubs between April and July 2016. To be eligible to participate, young people had to be aged between 8-16 years and fans of the Australian Football League (AFL - one of Australia's most prominent and publicised sports). Parents were approached and asked if their child was a self-identified AFL fan because the

207 study specifically sought to understand the opinions of young people who were 
engaged with a sport which had significant gambling advertising at stadiums, within broadcasts and had sponsorship relationships with teams (Thomas et al., 2012). If

210 eligible, multiple children from the same family group were able to participate. On

211 completion of initial interviews using a snowball sampling technique (Sadler et al.,

212 2010), parents were asked to pass on study details to other families who they

213 thought may have been eligible and interested in participating in the research

214 project. Prior to participation, parents were provided with a plain language statement

215 that provided information about the study. Each participant provided verbal and / or

216 written consent prior to participation. At the conclusion of the study each child

217 received a $\$ 30$ gift card to reimburse them for their time. Ethical approval for the

218 research was obtained from the Human Research Ethics Committee prior to data

219 collection commencing.

Data collection

223 Face to face semi-structured interviews were conducted with two researchers attending the interviews at an agreed location. One researcher interviewed the parent while the other interviewed the child. Interviews lasted between 30 and 45 minutes and were audio-taped with parents and young people interviewed out of immediate hearing range of each other. In instances where multiple children from the same family group participated each child was interviewed separately. While the broader study explored children's recall and awareness of sports betting advertising and their future gambling behaviours, parents and young people were asked a range

231 of open-ended questions relating to their perceptions of the sports betting industry,

232 how it promoted gambling products, the gambling industry's alignment with major 
233

234

235

236

237

238

239

240

241

242

243

244

245

246

247

248

249

250

251

252

253

254

255

256

257

sporting codes, any perceived positive or negative impact on young people, and strategies to prevent or reduce gambling harm for young people. To ensure anonymity, all data was de-identified prior to analysis.

\section{Data analysis}

Initial interviews were transcribed by author one or by a professional transcription company. Data analysis was a continuous process during data collection, with the interview schedule adjusted as new themes emerged. Data were reviewed to identify responses relevant to each of the three research questions, with constant comparison between parent and young people's responses. Although responses tended to appear in specific sections of the data set, data in the overall interview was explored and included for analysis if relevant. Data were managed using QSR NVivo 11. Author One led the data analysis process including reading and re-reading each transcript. Given the theory generating nature of CGT (Charmaz, 2006), initial coding allowed for the identification, development and revision of the emerging themes. As noted by Charmaz (2006), this first stage of coding enables considerations about the relevance of data in respect of research questions. Broad and then more specific themes were developed to reflect responses in relation to each of the key research questions. Throughout the data analysis process, discussions between the authors occurred regularly in relation to the emerging themes and their relevance to the research questions. Data collection and subsequent analysis was finalised when we had collected sufficient data to illustrate a range of concepts and ideas in relation to the research questions. Although qualitative data does not seek to attribute numerical values to data, in reporting the results of the data we have indicated 'a 
258 few' to represent less than $25 \%$ of participants, 'some' as up to $50 \%$, 'many' as up to

$25975 \%$ and 'most' as over $75 \%$ agreement.

260

261 Results

262

263 Sample description

264

265 The sample comprised 30 family groups, consisting of 29 parents and one

266 grandparent (subsequently referred to as parents) and 48 young people.

267 Approximately two thirds of the parent group were women $(n=19,65.5 \%)$, with an average age of 47.5 years. The majority of young people were boys $(n=41,85.4 \%)$, with an average age of 11.4 years. Family groups had similar socio-demographic attributes, all residing in suburbs of relative advantage, placing between the $6^{\text {th }}$ and

$2710^{\text {th }}$ decile according to the Index of Relative Socioeconomic Disadvantage

272 (Australian Bureau of Statistics, 2011).

274 A range of themes and subthemes emerged from the data in relation to the research 275 questions.

276

277 1. Perceptions of promotional strategies used by the gambling industry in the $278 \quad$ context of sports

280 Parents and young people were able to describe a range of strategies used by the sports betting industry to promote their products. These strategies could be clustered

282 into three themes: 1) the use of imagery and appeal strategies within advertising; 2) 
283 the normalisation of betting via advertising saturation; and 3) the alignment of betting

284 with sporting codes.

285

286 The use of imagery and appeal strategies within advertising

287

288 Parents and young people identified similar imagery and appeal strategies used within sports betting advertising including positive imagery, the use of celebrities, and incentives and inducements.

292 The use of positive imagery was particularly related to the social practices

293 associated with sports betting. Mothers described imagery of groups of 'mates' or

294 peers having fun betting together in social settings, stating that this created a perception that sports betting was a harmless or 'innocuous form of recreation', with many positive social benefits. One mother commented that by depicting groups of

297 people gambling together, sports betting was seen as a way to socialise with friends.

298 Fathers commented that advertising made betting appear as an extension of watching sport, with betting appearing as 'part of a package' with watching sport, drinking beer and sports betting all occurring together. In contrast to parents, young people under the age of 11 focused on the emotions depicted in the advertisements.

302 They emphasised the positive emotions of the actors in the advertisements and

303 linked this to the likelihood of winning money, speaking about 'happy people' or 304 'people cheering' within advertising. However, young people over the age of 11 provided a similar response to parents, commenting that imagery in advertising created a perception that gambling was a fun and social activity and something you 
307 do with friends, describing advertisements as depicting gambling 'with your mates' and appearing to 'have a good time'.

310 One specific appeal strategy identified by both parents and young people was the use of celebrities within advertising. Parents were particularly critical of this strategy,

312 with one parent describing these strategies as having an 'insidious' impact on young

313 people. Young people also commented that celebrities and 'big names' were used to

314 promote sports betting and noted that these strategies would be influential, as

315 athletes were perceived as 'role models'. For example, talking about the use of a

316 football player in sports betting commercials, one eight year old stated that: '...he could say something that sounds cool and you will probably want to try

321 At times, young people appeared to have quite a sophisticated understanding of advertising. For example, some young people also stated that celebrity endorsement of sports betting products lessened the perception of risks associated with these

324 products for young people, and thought that if celebrities or well-known people were engaging in sports betting it would be perceived as a less risky activity because they were trustworthy.

A range of other appeal strategies also decreased perceptions of risk associated with sports betting. For example, some parents stated that certain promotional

330 strategies, including incentives and inducements, created a perception that an

331 individual could control the outcome of sports betting and that an individual was 
332 more likely to win. In particular, parents commented on advertisements that promoted 'bonus bets' and 'money back' deals: commented:

Similarly, young people described how deals such as cash back offers gave the impression that gambling was not 'as risky'. For example, one 10-year-old boy

Finally, young people commented that different appeal strategies would have an influence on different groups of children. For example, cartoons used in advertising were perceived to have a particular influence on younger children, whereas strategies using humour and celebrity endorsement would appeal to teenagers.

The normalisation of gambling via advertising saturation

354 Parents and young people perceived that saturation-advertising techniques were designed to normalise and increase the social acceptability of sport betting. For example, parents discussed how the saturation of advertisements created the 
perception that betting on sport was 'very normal', 'very common', and that 'everyone

358 does it'. Both the volume and repetition of advertisements in key events, particularly within sport, were seen as perpetuating the notion that sports betting was an activity that all sports fans participated in: "Just sort of like they were making [sports betting] it a socially acceptable thing to do you know. Come along tonight... come to the footy and put a bet on, like it's something you do. Like 'come to the footy and have a pie, you know everyones' doing it'." - 45-year-old mother

Boys over the age of 11 also commented that the saturation of sports betting advertising created a perception that betting on sport was a normal and popular activity: “...Advertising makes it appear like so many people do it ... that it is really

Promotions that align gambling with sport popular."-- 13-year-old boy

Parents and some young people recognised that the alignment between betting companies and sporting codes was a key strategy used by the betting industry to positively influence attitudes towards betting. Some parents commented that this alignment was potentially an attempt to make sports betting appear 'family friendly' and a credible part of the sporting experience. Most parents were extremely critical

381 of these relationships. For example, one father stated: 
"I don't think the AFL is putting anything out about the impact of gambling or you know, any negative impacts of gambling. I would say that by promoting their sponsors they are promoting that sponsor's product..." - 44-year-old

While some young people identified the relationships between gambling companies and sporting codes, the influence of these relationships was more complex for them to consider. For example, young people described gambling companies and sporting codes as 'being together' and understood that there were financial relationships between the two industries. This was demonstrated by a few young people over the age of 11 who stated that some sporting codes appeared to be positive towards and encouraging of sports betting through their promotions that appeared to associate sporting codes with sports betting companies. Some also perceived that there were some financial benefits for sporting codes because of sponsorship relationships and that these outweighed any negatives from gambling.

I think it almost outweighs the negatives, 'cause that's a lot of money for them and again, it's the AFL (Australian Football League), it's a big thing you know..." - 13-year-old boy

402

\section{Proposed strategies for gambling harm prevention and reduction}

405 Suggestions for preventing and reducing the harms associated with sports related 406 gambling, clustered around three themes: 1) regulating advertising; 2) developing 
407 effective education strategies for young people; and 3) increased acceptance for

408 responsibility by governments and sporting organisations.

409

$410 \quad$ Regulating advertising

411

412 There were some clear similarities in suggestions from parents and young people in

413 restricting sports betting advertising. For example, both parents and young people

414 advocated for 'capping' the number of advertisements to reduce the perception of 'ad

415 after ad after ad'. Some (and particularly young people) believed that a complete ban

416 was required. Parents often drew parallels with advertising restrictions for other

417 products such as tobacco and alcohol. Parents argued that sports betting marketing

418 should be addressed in a similar way to these products, particularly relating to a

419 complete ban of advertising in sport as had been implemented for tobacco products.

420 “...if you could cut out advertising, I'd just cut it... let's see sports betting in the same way that we saw cigarette advertising..." - 46-year-old mother

424 While young people also advocated for bans or restrictions on the timing of advertising, they were much more sceptical about whether the government would be prepared to implement such restrictions. Some were critical about the willingness of policy makers and sporting codes to act in the best interests of young people. These young people were aware that advertising was a key strategy to help the sports betting industry make money: 
"It would be good if you could like stop the ads, because the ads are influencing a lot... I don't think you would be able to stop betting, like in total. But if the ads go away sports betting won't get as much money, which means less people bet because less people actually think about it." - 12-year-old boy

One boy suggested that while a complete ban on advertisements was needed, he questioned whether the government would actually implement this:

"Well I think they could actually stop it, but I don't think the government actually would." - 12-year-old boy

A few young people also commented that even if advertising was restricted to traditional media platforms such as television, companies would always find a way to advertise. For example, one boy described the presence of advertising for gambling products on social media as a way that companies could circumvent such restrictions.

Developing effective education strategies

Both parents and young people discussed the role of education in helping young people to understand the risks associated with gambling and the strategies of the gambling industry. Parents commented on the need for educational programs that would be similar to those offered for tobacco and alcohol products, which aimed to denormalise or 'unglamorise' sports betting. Parents stressed the importance of hard hitting educational campaigns that identified the potential for negative outcomes 
associated with gambling. While parents believed that education could come from a wide range of individuals and organisations, some were more reflective about the effectiveness of education. These parents argued that ultimately regulation of the gambling industry was needed to reduce harm. However, some parents stated that education about the risks associated with gambling would have limited impact because 'people don't think it is going to happen to them, until it does happen to them'. Young people also emphasised education as one way to prevent potential gambling harm amongst their peers but that this needed to be included within a range of strategies to prevent harm. Some young people suggested the integration of gambling education in the classroom by 'doing things with odds in maths', while others suggested that education campaigns at schools might be helpful in making young people aware of the 'dangers' associated with gambling. Some young people believed that education needed to focus on the 'real risks' of gambling and emphasise the rate at which 'you win and lose' when placing a bet. Some young people over the age of 11 suggested that organisations or individuals with a lived experience of gambling harm could come to their school and talk to students, believing this would be helpful in increasing their understanding of the potential risks associated with sports betting and gambling more generally. "I think they [the government] could do the same kind of thing they do with drugs and alcohol, but they don't do it with things like gambling, so they could 
481 A small number of parents perceived that the financial incentives for governments

482 from gambling resulted in a lack of effective regulation. These parents believed that governments needed to be 'independent' from the financial interests of gambling

484 organisations. A parent commented that there was room for governments to regulate 485 'the way that corporates promote their products'. A few parents made a number of 486 policy recommendations. For example, they identified the need for consistency in 487 both state and federal legislation to address sports betting advertising. Parents suggested that governments could approach gambling harm reduction in a similar way to regulations on tobacco products. This was echoed by a small number of 490 young people:

491 "You know how with smoking there's the thing on the back which says, 'smoking is super dangerous'... they could write gambling probably won't give you all the money that you pay, or more." - 12-year-old boy

Young people were often aware that gambling advertisements could be problematic, and proposed logical solutions for reducing young peoples exposure to advertising. For example, one 11-year-old boy stated that the clear way to reduce the number of advertisements was to have fewer gambling companies: “There just needs to be less. If there were less, people wouldn't care as much,

504 Parents also discussed the responsibilities of sporting codes in reducing young 505 people's exposure to advertising. For example, parents commented that the 
506 government could subsidise the AFL to reduce its reliance on gambling industry

507 sponsorship and encourage them to 'find other sponsors'. Parents clearly articulated

508 that sporting codes and the gambling industry needed separation from each other:

"I think there should be a separation. That none of the AFL or the clubs should have any licensing, sponsorship or advertising money generated from gambling." - 51-year-old mother

514 Parents also commented that the sporting codes needed to be aware of their young

515 fan base and the inconsistency between sponsors who promoted gambling and the

516 family friendly framing of the game:

"I would like to think that [the AFL] would say 'if we are going to be more consistent in our message then we are going to see less gambling and more wholesome products'. " - 52-year-old father

Young people identified various strategies that sporting codes could implement in the community, including emphasising the risks associated with gambling, reducing sponsorship relationships, and using sportspeople to help educate individuals about the risks associated with gambling: band together to take action..." - 12-year-old boy

\section{Discussion}


532 This study sought to explore parents' and young peoples' perceptions of and

533 attitudes towards the promotional strategies used by the sports betting industry

534 during sport and identify strategies to reduce and prevent gambling harm. While

535 previous research has documented community attitudes towards other unhealthy

536 commodity industries (Rosenberg et al., 2012, Tobin et al., 2011, Smith et al., 2017),

537 less is known about attitudes towards the gambling industry, recognition of their

538 strategies, and community recommendations about how to reduce gambling harm.

539 The findings of this study raise a number of key points for discussion.

541 Both parents and young people perceived that the gambling industry used incentives and appealing imagery, normalised betting through saturation-advertising, and associated gambling with family friendly sporting codes in their advertisements,

544 when framing their products in the community. Some parents noted similarities with

545 previously popularised products such as tobacco and alcohol. In considering

546 responses to gambling advertising, parents often drew on the historical template

547 provided by tobacco control. Reflecting on tobacco and alcohol regulations, some

548 parents believed that similar regulations might be suitable in the context of gambling,

549 particularly those focusing on advertising. Similarly to parents, a few young people

550 also referred to tobacco control strategies when discussing the potential use of

551 warning labels as a harm prevention strategy in gambling suggesting that a similar

552 approach could be useful. This demonstrates that community members are able to

553 use other reference points in public health in considering effective responses to new

554 and emerging public health issues. 
555 Parents also recognised the financial relationships between sports betting companies and sports and were concerned about the potential impact this had on the way their products were presented to the consumer, referring specifically to the conflicts of interest that could arise. However, young people were less cognisant of

559 the potential for negative outcomes associated with these relationships, rather 560 acknowledging that these relationships could create a positive image of gambling, with some young people in turn suggesting that they might make people want to gamble. Both parents and young people questioned the impact of sporting codes' relationships with gambling companies and were worried about how this could

564 influence young people's perceptions of sports betting and the potential harm associated with gambling. Some young people also noted that these relationships could encourage gambling amongst their peers and downplay the risk of harm. The strategies engaged in by gambling companies are not dissimilar to those that have been used by other unhealthy commodity industries (Thomas et al., 2016b, Story and French, 2003, Bond et al., 2010). Both parents and young people were able to

570 describe some of these strategies (Pettigrew et al., 2013, Smith et al., 2017), and recognised similarities across industries. In proposing solutions to address gambling harm, young people acknowledged the impact that advertising could have on people's perceptions. This may be as a result of the media and technologically

574 focused environments to which young people are exposed to and aware of, in 575 comparison to older generations (such as parents). Young people, and particularly 576 those over the age of 11 , generally demonstrated a sophisticated understanding of 577 the potential negative consequences of gambling, and particularly the new media 578 environments that promoted these products. Similarly to parents they were able to 579 identify a range of promotional strategies sports betting companies appeared to 
employ in their advertisements. Although young people demonstrated in-depth critical analysis skills when recognising and subsequently discussing these strategies, they did not appear to fully appreciate the subtleties and complexities associated with responding to these problems. Nevertheless, there is significant potential to engage young people and parents in community-led responses to gambling reform; particularly given that young people and their parents seem to understand the implications of unhealthy commodity marketing on young people.

While both parents and young people emphasised that education was important in reducing and preventing gambling related harm, prior literature in this area

590 acknowledges that although education is important, it should be considered as part

591 of a broader public health and health promotion approach (Frieden, 2014, Nutbeam, 2000). Evidence from tobacco control suggests that school-based harm reduction strategies have mixed success, with limited evidence of their long-term impact

594 (Scollo and Winstanley, 2012). Evidence also suggests that industries promoting unhealthy products (e.g. tobacco and alcohol) are often supportive of harm reduction and prevention strategies that are known to be less effective (Scollo and Winstanley, 2012, Miller et al., 2011). Providing similar responses, parents and young people both suggested that gambling awareness should be integrated into school curricula.

599 While this would provide young people with further opportunities to be educated 600 about gambling harm, there would be a need for evidence to justify this approach, 601 particularly given the many pressures on the school curriculum that already often preclude an increase in focus on health and physical education topics. 
604 Overall both parents and young people agreed that restricting sports betting

605 advertising was the best way to prevent and reduce gambling harm in the

606 community. Parents and young people alike frequently referred to the potential

607 negative impact of gambling advertising on community perceptions about gambling

608 harm and risk. While there have been some regulatory changes restricting the times

609 sports betting advertisements can be shown (Australian Communications and Media

610 Authority, 2018), at present a complete ban or any other significant restrictions on

611 gambling advertisements have not been implemented.

612

613 The inclusion of young people's opinions and engagement in policy development

614 and advocacy should also be considered. The results of this study indicate that

615 young people are both aware of and have clear opinions about ways to reduce

616 gambling harm among their peers and the broader community. Some young people

617 spoke of known harm reduction strategies implemented in other industries (e.g.

618 warning labels on tobacco products), which have been successful in increasing

619 community awareness about the health risks associated with smoking (Azagba and

620 Sharaf, 2013, Scollo and Winstanley, 2012). The responses from young people

621 further suggest that when developing and implementing harm prevention and health

622 promotion strategies, they would rather be 'engaged with' as opposed to 'talked to'.

623 Young people noted the potential positive influence that sporting personalities or

624 individuals with a lived experience of gambling harm may have when being educated

625 about gambling harm. Given the high level of awareness about gambling among

626 young people, it is important to consider ways for public health advocates to more

627 effectively engage with young people. Projects that have demonstrated success with

628 parents could be adapted to engage young people, for example "Parents Voice" 
629 which, particularly through its "Parents Jury", has been effective in communicating

630 parental concerns around their children's exposure to inappropriate food promotion

631 (Gannon et al., 2014). Youth ambassadors have also been used successfully to

632 advocate for a variety of tobacco control measures (Tobacco Free Kids, 2018).

633 Consequently, there should be scope for those working to address gambling harm to

634 create similar opportunities to directly engage with and use young people's voices in

635 both policy and education efforts. However, this study shows that young people are

636 at times sceptical about their role and engagement with governments when

637 addressing gambling harm. It is important to ensure that those who engage with

638 young people in the future fully investigate their attitudes and opinions, present their

639 views, and encourage their active involvement in developing and supporting the

640 most effective public health advocacy strategies to prevent and reduce gambling

641 harm.

642

643 This study has a number of limitations. First, the study recruited family groups whose

644 children were fans of the AFL which has a high saturation of sports betting marketing

645 (Thomas et al., 2012). Therefore, these young people may have had a greater level

646 of awareness of sports betting advertising and marketing compared to those who are

647 fans of other sports with a lower saturation of advertisements. Consequently, their

648 views, particularly towards sporting codes may not apply to young people who are

649 not fans of AFL. The use of convenience and snowball sampling techniques in this

650 study resulted in family groups from more affluent socio-demographic backgrounds.

651 This reduces the generalisability of the current study and should be considered in

652 future research into community attitudes of sports betting and its potential for harm.

653 Further, the majority of parents sampled in this study were mothers, and the majority 
654 of young people interviewed were boys. These sub-groups may have different perspectives towards sport and betting. Future research into community attitudes and opinions should seek to sample a more even distribution of boys and girls, and

657 mothers and fathers.

658

\section{Conclusion}

660 Parents and young people clearly identified and recommended a number of

661 strategies to reduce gambling harm including restricting sports betting

662 advertisements, increasing gambling awareness, and education. The common view

663 of the study participants was that there is a need for greater advertising restrictions.

664 This could include the removal of sports betting advertising during all live sporting 665 telecasts (inclusive of advertising breaks and breaks in play), restricting the imagery 666 and depiction of gambling in advertisements and restricting the number of sports

667 betting advertisements in a given time period. Implementing these types of 668 regulatory changes appears to be warranted and reflects the sentiments of parents 669 and young people. Further, given the demonstrated level of understanding about the 670 issue of gambling from parents and young people, engaging with this group through

671 similar programs to the "Parents Jury" may provide a unique opportunity to ensure

672 that the attitudes and opinions of the community are recognised during future 673 advocacy efforts and policy debates. Finally, those working in public health should 674 explore the various measures used in other areas of public health and health 675 promotion to more effectively engage with and involve the community, and 676 particularly young people, in future harm prevention and health promotion initiatives. 
679 Australian Football League: AFL

680 Constructivist Grounded Theory: CGT

681 DECLARATIONS

682 Acknowledgements

683 We would like to acknowledge our study participants for their contribution to this

684 project.

685

Consent for publication

686

Participants consented to the data being used for publication.

687

688

689

690

691

692

693

694

695

696

697

698

699

700

701

702

703

704

705

706

707

708

709

710

711

712

713

714

\section{Availability of data and material}

This data will not be made available to ensure the privacy and confidentiality of the study participants.

\section{References (1,155 words)}

Australian Bureau of Statistics. Snapshots of Australia: Census of Population and Housing. Commonwealth of Australia. 2011. Available: http://stat.data.abs.gov.au/Index.aspx?DataSetCode=ABS_SEIFA_LGA [Accessed 22nd March 2018].

Australian Communications and Media Authority. 2018. Broadcasting Services (Online Content Service Provider Rules) 2018 [Online]. Available:

https://www.legislation.gov.au/Details/F2018L01203 [Accessed 26 Nov 2018].

Azagba, S. \& Sharaf, M. F. 2013. The effect of graphic cigarette warning labels on smoking behavior: evidence from the Canadian experience. Nicotine and Tobacco Research, 15, 708-17.

Bestman, A., Thomas, S. L., Randle, M. \& Thomas, S. D. 2015. Children's implicit recall of junk food, alcohol and gambling sponsorship in Australian sport. BMC Public Health, 15, 1022.

Bond, L., Daube, M. \& Chikritzhs, T. 2010. Selling addictions: similarities in approaches between big tobacco and big booze. Australasian Medical Journal, 3, 325-332.

Carlisle, S. 2000. Health promotion, advocacy and health inequalities: a conceptual framework. Health Promotion International, 15, 369-376.

Charmaz, K. 2006. Constructing grounded theory: a practical guide through qualitative analysis (Introducing Qualitative Methods Series).

Conlisk, E., Proescholdbell, S. K. \& Pan, W. K. 2006. Support for tobacco control policies among youth in North Carolina. North Carolina Medical Journal, 67, 175-9. 
Crawford, M. A., Balch, G. I. \& Mermelstein, R. 2002. Responses to tobacco control policies among youth. Tobacco Control, 11, 14-19.

FARE Australia. Annual Alcohol Poll 2017: attitudes and behaviours. Foundation of Alcohol Research and Education. 2017. Available: http://fare.org.au/wpcontent/uploads/FARE-ANNUAL-ALCOHOL-POLL-2017-REPORTFINAL_DIGITAL.pdf [Accessed 12th March 2018].

Frieden, T. R. 2014. Six components necessary for effective public health program implementation. American Journal of Public Health, 104, 17-22.

Gannon, D., Pryor, A. \& Mallon, A. 2014. The parents jury healthy checkouts campaign. Obesity Research \& Clinical Practice, 8, 34.

Hesketh, K., Waters, E., Green, J., Salmon, L. \& Williams, J. 2005. Healthy eating, activity and obesity prevention: a qualitative study of parent and child perceptions in Australia. Health Promotion International, 20, 19-26.

Kickbusch, I. Action on health promotion: approaches to advocacy and implementation Copenhagen, Denmark: World Health Organization. 1995. [Accessed 18 January 2018].

Lancaster, K., Ritter, A. \& Matthew-Simmons, F. Young people's opinions on alcohol and other drugs policy-national survey results. Australian National Council on Drugs. 2014. Available: https://ndarc.med.unsw.edu.au/sites/default/files/newsevents/events/RP27young-peoples-opinions.pdf [Accessed 12th March 2018].

Lopez-Gonzalez, H., Estévez, A. \& Griffiths, M. D. 2017. Marketing and advertising online sports betting: a problem gambling perspective. Journal of Sport and Social Issues, 41, 256-272.

McAllister, I. 2014. Public opinion towards gambling and gambling regulation in Australia. International Gambling Studies, 14, 146-160.

Miller, P. G., De Groot, F., McKenzie, S. \& Droste, N. 2011. Vested interests in addiction research and policy. Alcohol industry use of social aspect public relations organizations against preventative health measures. Addiction, 106, 1560-7.

Montini, T., George, A., Martin-Mollard, M. \& Bero, L. A. 2010. The role of public participation in public health initiatives: an analysis of the WHO Framework Convention on Tobacco Control. Global Public Health, 5, 48-61.

Nutbeam, D. 2000. Health literacy as a public health goal: a challenge for contemporary health education and communication strategies into the $21 \mathrm{st}$ century. Health Promotion International, 15, 259-267.

Odukoya, O. O., Chife, J. O., Odeyemi, K. A. \& Nwangwu, G. I. 2015. Young peoples awareness and support for tobacco control legislation: a study among inschool youth in Lagos, Nigeria. Nigerian Quarterly Journal of Hospital Medicine, 25, 193-201.

Pettigrew, S., Rosenberg, M., Ferguson, R., Houghton, S. \& Wood, L. 2013. Game on: do children absorb sports sponsorship messages? Public Health Nutrition, 16, 2197-2204.

Pitt, H., Thomas, S. L., Bestman, A., Stoneham, M. \& Daube, M. 2016a. "It's just everywhere!" children and parents discuss the marketing of sports wagering in Australia. Australian and New Zealand Journal of Public Health, 40, 480-486.

Pitt, H., Thomas, S. L. \& Bestman, A. 2016b. Initiation, influence, and impact: adolescents and parents discuss the marketing of gambling products during Australian sporting matches. BMC Public Health, 16, 1-12. 
Pitt, H., Thomas, S. L., Bestman, A., Daube, M. \& Derevensky, J. 2017a. Factors that influence children's gambling attitudes and consumption intentions: lessons for gambling harm prevention research, policies and advocacy strategies. Harm Reduction Journal, 14, 11.

Pitt, H., Thomas, S. L., Bestman, A., Daube, M. \& Derevensky, J. 2017b. What do children observe and learn from televised sports betting advertisements? A qualitative study among Australian children. Australian and New Zealand Journal of Public Health, 41, 604-610.

Potvin, L., Cargo, M., McComber, A. M., Delormier, T. \& Macaulay, A. C. 2003. Implementing participatory intervention and research in communities: lessons from the Kahnawake Schools Diabetes Prevention Project in Canada. Social Science \& Medicine, 56, 1295-1305.

Ritchie, J., Lewis, J., McNaughton Nicholls, C. \& Ormston, R. 2014. Qualitative research practice: a guide for social science students and researchers, Los Angeles, California, SAGE Publications, Inc., Second edition.

Rosenberg, M., Pettigrew, S., Wood, L., Ferguson, R. \& Houghton, S. 2012. Public support for tobacco control policy extensions in Western Australia: a crosssectional study. BMJ open, 2.

Sadler, G. R., Lee, H.-C., Lim, R. S.-H. \& Fullerton, J. 2010. Recruitment of hard-toreach population subgroups via adaptations of the snowball sampling strategy. Nursing and Health Sciences, 12, 369-374.

Scollo, M. \& Winstanley, M. Tobacco in Australia: facts and issues. Melbourne 2012. Available: http://www.tobaccoinaustralia.org.au [Accessed 14th March 2018].

Smith, M., Signal, L., Edwards, R. \& Hoek, J. 2017. Children's and parents' opinions on the sport-related food environment: a systematic review. Obesity Reviews, 18, 1018-1039.

Story, M. \& French, S. 2003. Food advertising and marketing directed at children and adolescents in the US. International Journal of Behavioral Nutrition and Physical Activity, 1.

Thomas, S. L., Lewis, S., Duong, J. \& McLeod, C. 2012. Sports betting marketing during sporting events: a stadium and broadcast census of Australian Football League matches. Australian and New Zealand Journal of Public Health, 36, 145-152.

Thomas, S. L., Pitt, H., Bestman, A., Randle, M., Daube, M. \& Pettigrew, S. Child and parent recall of gambling sponsorship in Australian sport. Victorian Responsible Gambling Foundation. 2016a. Available: https://responsiblegambling.vic.gov.au/resources/publications/child-andparent-recall-of-gambling-sponsorship-in-australian-sport-67/ [Accessed 17th August 2017].

Thomas, S. L., David, J., Randle, M., Daube, M. \& Senior, K. 2016b. Gambling advocacy: lessons from tobacco, alcohol and junk food. Australian and New Zealand Journal of Public Health, 40, 211-217.

Thomas, S. L., Randle, M., Bestman, A., Pitt, H., Bowe, S. J., Cowlishaw, S., et al. 2017. Public attitudes towards gambling product harm and harm reduction strategies: an online study of 16-88 year olds in Victoria, Australia. Harm Reduction Journal, 14, 49.

Thomas, S. L., Bestman, A., Pitt, H., Cassidy, R., McCarthy, S., Nyemcsok, C., et al. 2018. Young people's awareness of the timing and placement of gambling advertising on traditional and social media platforms: a study of 11-16-yearolds in Australia. Harm Reduction Journal, 15, 51. 
814 Tobacco Free Kids. 2018. Tobacco Free Kids Youth Advocacy Initiatives [Online].

815 Available: https://www.kickbuttsday.org/for-youth-

816 advocates/advocacy_initiatives/ [Accessed 6th March 2018].

817 Tobin, C., Moodie, A. R. \& Livingstone, C. 2011. A review of public opinion towards

818 alcohol controls in Australia. BMC Public Health, 11, 58.

819 World Health Organization. 1986. The Ottawa Charter for Health Promotion [Online]. Genva, Switzerland: World Health Organization. Available: http://www.who.int/healthpromotion/conferences/previous/ottawa/en/ [Accessed 12th March 2018]. 